\title{
Diagnosis of severe mitral regurgitation due to non-rheumatic chordal abnormalities
}

\author{
G. C. Sutton, K. Chatterjee, ${ }^{1}$ and P. K. Caves ${ }^{2}$ \\ From the Department of Cardiology, Brompton Hospital, London
}

Twenty-one patients with severe non-rheumatic mitral regurgitation due to rupture or stretching of the mitral chordae tendineae have been investigated by phonocardiography, left ventricular displacement records, and external carotid records. The findings have been related to the haemodynamic derangement measured at cardiac catheterization, the anatomical lesion seen at open heart operation, and the aetiology. Left ventricular function has been assessed by angiographically determined ejection fraction.

Typical phonocardiographic findings included a 'diamond-shaped' pansystolic murmur (62\%), abnormally wide splitting in expiration of the second heart sound (50\%), with accentuation of the pulmonary component $(89 \%)$, and a third heart sound $(43 \%)$. The ' $a$ ' wave in the displacement record was exaggerated $(90 \%)$ and a third heart sound point was frequently recorded ( $55 \%)$. There was shortening of left ventricular electromechanical systole and left ventricular ejection time by comparison with normal values. Values for the preejection period were variable. From these external recordings it was not possible to predict the anatomical site of the lesion (cusp or papillary muscle), the level of pulmonary artery pressure, the aetiology (idiopathic or with a prior history of myocardial infarction), or the state of left ventricular function as judged by ejection fraction. Ejection fraction separated those patients with an idiopathic aetiology from those who had prior myocardial infarction.

The usual physical signs of non-rheumatic mitral regurgitation due to ruptured chordae tendineae of the mitral valve include sinus rhythm, a widely conducted systolic murmur with an accompanying thrill, third and fourth heart sounds at the cardiac apex, and a hyperdynamic cardiac impulse. Such physical findings may be influenced by various factors including the cusp involved (Edwards and Burchell, 1958; Selzer et al., 1967), the papillary muscle from which the chordae are detached, the duration and severity of the mitral regurgitation (Selzer et al., 1967; Sanders et al., 1965), and the aetiology. It is also possible that the state of left ventricular function may modify the physical signs.

The present study was carried out to determine the role of these factors in the production of some of the physical signs in 21 patients with chordal abnormalities not associated with rheumatic heart disease and resulting in severe mitral regurgitation.

Received 2I December 1972.

1 Present address: Department of Cardiology, Cedars-Sinai Medical Center, Cedars of Lebanon Hospital Division, Los Angeles, California, U.S.A.

2 Present address: Department of Cardiovascular Surgery, Stanford University, Palo Alto, California, U.S.A.
Before operation all patients had cardiac catheterization and left ventriculography, enabling measurement of right and left heart pressures, the severity of mitral regurgitation, and the ejection fraction to be assessed. In all patients the precise anatomy of the chordal lesion was seen at operation. The haemodynamic and operative findings and the ejection fraction were related to the physical signs documented by phonocardiography and left ventricular displacement records and to the systolic time intervals measured from external carotid artery records.

\section{Subjects}

\section{Aetiology}

Idiopathic Twelve patients (age range 45 to 82 years, 7 men and 5 women) had no obvious predisposing factor for rupture (10) or stretching (2) of the mitral chordae tendineae. Two other patients (a boy aged 7 and a woman aged 19 who developed ruptured chordae during pregnancy) (Caves and Paneth, 1972) are included with this group of patients and classified as 'idiopathic'.

Infarct Seven patients had a previous history and electrocardiographic evidence of myocardial infarction 
(6 men, I woman, age range 54 to 69 years) occurring more than one year before this study. This group is classified as 'infarct'. Six of these patients had stretched chordae, and in only one were the chordae ruptured.

No patient in either group had a history of rheumatic fever or bacterial endocarditis, nor was there any evidence of rheumatic heart disease at operation. No other valvular abnormalities apart from mitral regurgitation were present.

\section{Cusp and papillary muscle lesion}

The patients have also been divided according to the cusp to which the involved chordae tendineae were attached and to the papillary muscle from which these abnormal chordae originated. In the 'idiopathic' group the posterior cusp chordae were ruptured in 8 patients and stretched in 2, while only 3 had isolated rupture of the aortic cusp chordae. One patient had rupture of the chordae to both leaflets. By contrast, in the 'infarct' group 6 patients had stretched aortic cusp chordae (one patient had stretched chordae to the posterior cusp in addition), and only one patient had rupture of the aortic cusp chordae. In the series as a whole, the aortic cusp was involved in 9 patients, the posterior in ro, and both cusps in 2.

The papillary muscle from which the involved chordae originated was often difficult to assess at operation. Ruptured chordae to the central portion of a cusp were always assumed to have originated from both papillary muscles. There were 16 such patients in the series, some of whom had rupture of all chordae to one leaflet. Three patients had rupture of chordae originating from the posteromedial papillary muscle and 2 of chordae originating from the anterolateral papillary muscle.

\section{Left ventricular function}

Seventeen of the 2 I patients had angiograms technically adequate for the measurement of ejection fraction as an index of left ventricular function. These patients were divided into two groups according to the ejection fraction (normal value in this laboratory $0.70 \pm 0.03$ ) (Chatterjee et al., 197I). Ten patients had normal ejection fraction (range $0.64-0.86$ ) while 7 patients had a reduced ejection fraction (range $0.22-0.56$ ). All patients with normal ejection fractions were in the 'idiopathic' group. Of the 7 patients with reduced ejection fraction, 6 patients were in the' infarct' group and only $I$ patient was in the 'idiopathic' group.

\section{Methods \\ External recordings \\ All records were made using a Cambridge photographic multichannel recorder at a paper speed of $100 \mathrm{~mm} / \mathrm{sec}$. All phonocardiograms were made with the patient supine at $45^{\circ}$ using Cambridge microphones with simultaneous records in pulmonary and mitral areas. External carotid records were made simultaneously with the phonocardio- grams and electrocardiograms using a sensing device}

and transducer ${ }^{1}$ held by hand over the right carotid artery. The same instrument was used to record the displacement of the intercostal space relative to the ribs at the location of the maximal impulse with the patient in the left lateral decubitus position at $45^{\circ}$.

Analysis of records The phonocardiogram in the mitral area was analysed for the shape and duration of the systolic murmur, the presence of third and fourth heart sounds, diastolic murmurs, and additional sounds. The phonocardiogram in the pulmonary area was used for analysis of the second heart sound with respect both to the width of splitting over several respiratory cycles and to the relative intensity of pulmonary $\left(P_{2}\right)$ and aortic $\left(\mathrm{A}_{2}\right)$ components.

The external carotid record was used to determine the left ventricular ejection time (from the onset of the upstroke to the dicrotic notch deriving a mean value over several cardiac cycles.)

Total left ventricular electromechanical systole was measured from the $Q$ wave in the electrocardiogram to $A_{2}$. The pre-ejection period was derived by subtracting left ventricular ejection time from left ventricular electromechanical systole. Note was made of the heart rate in order to derive a predicted normal value for each patient's sex and heart rate according to the formulae of Weissler, Harris, and Schoenfeld (1968). The differences between the observed and the predicted normal values for left ventricular electromechanical systole, preejection period, and left ventricular ejection time in each patient were thus derived. The ratio pre-ejection period to left ventricular ejection time was also derived.

The left ventricular displacement record was analysed with respect to the ' $a$ ' wave and the rapid filling wave. The height of the ' $a$ ' wave was related to the total height of the displacement record (from ' $E$ ' point to ' $O$ ' point) over several cardiac cycles, and a mean value obtained. The rapid filling wave either showed retraction following its peak ('third sound point') or there was continuing outward movement in diastole without abrupt retraction.

\section{Cardiac catheterization and angiographic findings}

Routine right and left heart catheterization was carried out, pressure measurements being referred to the midchest level. Left ventricular cineangiography was carried out with the patient in the right anterior oblique position, injecting approximately $\mathrm{I} \mathrm{ml} / \mathrm{kg}$ body weight of Triosil 75 per cent $^{2}$ with a pressure injector. Cardiac output was derived using the Fick principle. Pulmonary vascular (arteriolar) resistance was derived from the difference between the mean pulmonary and mean wedge pressure divided by the cardiac index and expressed as units $\times \mathrm{m}^{2}$. The left ventricular diastolic pressure was taken either as the height of the ' $a$ ' wave, if it was present, or 0.05 sec after the $Q$ wave of the electrocardiogram if an abrupt change of slope could not be identified. The ejection fraction ( $E F=$ left ventricular stroke volume/end-diastolic volume) was calculated from the left ventricular

\footnotetext{
1 Cambridge Scientific Instruments Ltd., Cambridge: time constant is $4 \mathrm{sec}$, low frequency limit of $0.04 \mathrm{cycles} / \mathrm{sec}$.

2 Sodium, calcium, and magnesium metrizoate. Glaxo Laboratories Ltd., Greenford, Middlesex.
} 
cineangiogram according to the technique previously described from this laboratory (Chatterjee et al., 1971).

\section{Results}

\section{Systolic murmur}

A pansystolic murmur was present in the mitral area in all but one patient (Table I). The murmur had a mid- or late-systolic crescendo followed by a diminuendo ('diamond-shape') in 13 patients $(62 \%)$ and was sometimes seen to extend beyond aortic valve closure $\left(\mathrm{A}_{2}\right)$ (Fig. I). Four patients $(19 \%)$ had a systolic murmur that began with the first heart sound and had a late crescendo to $A_{2}$ without any diminuendo. Three patients ( $14 \%$ ) had a pansystolic murmur without any accentuation. The only patient who did not have a pansystolic murmur had a decrescendo systolic murmur starting with the first heart sound but stopping before $\mathrm{A}_{2}$ ('early' systolic murmur). The characteristics of the systolic murmur were not related to the cusp involved by chordal rupture or stretching, or to the height of the pulmonary artery pressure, or to left ventricular function.

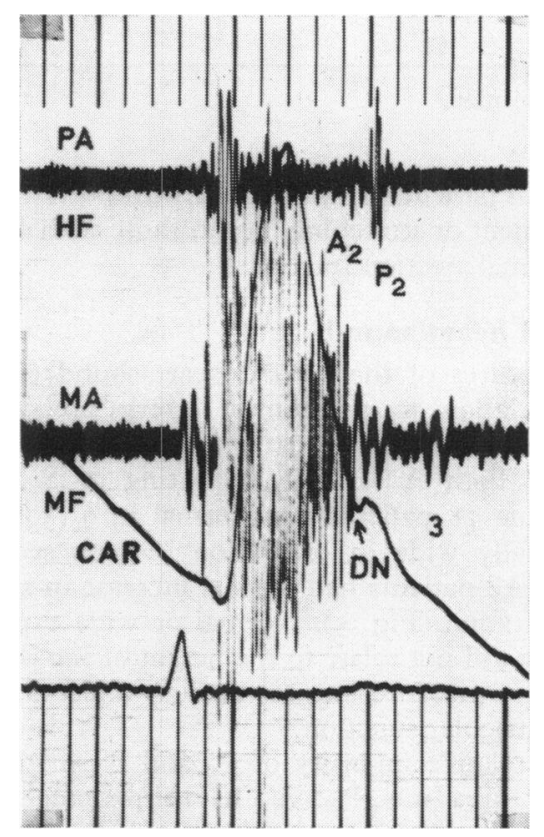

FIG. I Diamond-shaped systolic murmur in patient with ruptured chordae in the mitral area $(M A)$. Third heart sound (3) $0.12 \mathrm{sec}$ after $A_{2}$ in mitral area recorded using medium frequency filters $(M F)$. Carotid $(C A R)$ pulse tracing by means of the dicrotic notch $(D N)$ identifies $A_{2}$ and pulmonary valve closure $\left(P_{2}\right)$ in the pulmonary area $(P A)$ using high frequency filters $(H F)$. Time markers $0.04 \mathrm{sec}$.
Third heart sound and rapid filling wave

Nine patients $(43 \%)$ had a third heart sound $\left(S_{3}\right)$ recorded in the mitral area (Table $\mathrm{r}$ ). All of these had lesions affecting the posterior cusp, apart from the youngest patient who had detachment of the chordae to the aortic cusp. None was in the 'infarct' group. The timing of $S_{3}$ varied between 0.12 and $0.20 \mathrm{sec}$ after $\mathrm{A}_{2}$ (Fig. 2), and coincided with the peak of the rapid filling wave. All patients with an $S_{3}$ had obvious retraction following the peak of the rapid filling wave ('third sound point'). In addition, 3 other patients had a third sound point, but without an $S_{3}$ being recorded. Of the 12 patients $(57 \%)$ with an $S_{3}$ or a third sound point, $8(67 \%)$ had detachment or stretching of the chordae to the posterior cusp alone, while $3(25 \%)$ had aortic cusp detachment alone. Only 2 patients with a reduced ejection fraction in the 'infarct' group had a third sound point.

\section{Additional diastolic sounds and murmurs}

Three patients ( $14 \%$ ) had an additional early diastolic sound. The timing of the early diastolic sound varied between 0.07 and $0.16 \mathrm{sec}$ after $A_{2}$, coincided

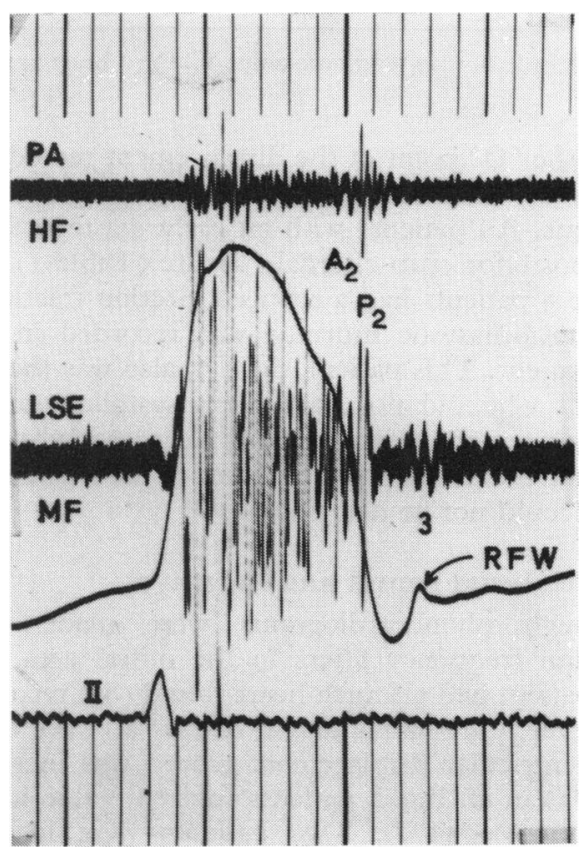

FIG. 2 Left ventricular displacement record showing the retraction following the peak of the rapid filling wave $(R F W)$. The peak of the rapid filling wave is coincident with a third heart sound (3) recorded at the left sternal edge (LSE). Lead II of the electrocardiogram recorded simultaneously. 
TABLE I Phonocardiographic and displacement record findings in patients divided according to mitral cusp affected

\begin{tabular}{|c|c|c|c|c|c|c|c|c|c|c|}
\hline & $\begin{array}{l}\text { Case } \\
\text { No. }\end{array}$ & $\begin{array}{l}\text { Age } \\
(y r)\end{array}$ & Sex & $\begin{array}{l}\text { Systolic } \\
\text { murmur }\end{array}$ & $S_{3}$ & $\begin{array}{l}\text { 3rd } \\
\text { sound } \\
\text { point }\end{array}$ & $\begin{array}{l}\text { Early } \\
\text { diastolic } \\
\text { sound }\end{array}$ & $\begin{array}{l}\text { Mid- } \\
\text { diastolic } \\
\text { murmur }\end{array}$ & $\begin{array}{l}\text { 'a'/total } \\
\text { height } \\
(\%)\end{array}$ & $\begin{array}{l}\text { Left ventricular } \\
\text { diastolic pressure } \\
(\mathrm{mmHg})\end{array}$ \\
\hline \multirow[t]{9}{*}{ Aortic cusp } & I & 7 & $M$ & Early & + & & - & + & & IO \\
\hline & 2 & 60 & $\mathbf{M}$ & Late crescendo & - & - & - & - & 16 & 9 \\
\hline & $3^{\star}$ & 57 & $\mathbf{M}$ & Diamond & - & - & - & - & 13 & 25 \\
\hline & 4 & 45 & $\mathbf{F}$ & Diamond & - & + & - & - & I9 & 20 \\
\hline & $5^{\star}$ & 69 & F & Diamond & - & - & - & - & 12 & 22 \\
\hline & $6^{\star}$ & 59 & $\mathbf{M}$ & Diamond & - & - & - & - & 24 & 36 \\
\hline & $7^{\star}$ & 63 & $\mathbf{M}$ & Diamond & - & - & - & - & 20 & 25 \\
\hline & 8 & 54 & F & Diamond & - & + & - & - & 19 & 28 \\
\hline & $9^{\star}$ & 64 & $\mathbf{M}$ & Diamond & - & - & - & - & 19 & 48 \\
\hline \multirow[t]{10}{*}{ Posterior cusp } & I0 & 56 & $\mathbf{F}$ & Diamond & + & + & + & - & 25 & 14 \\
\hline & $I I^{\star}$ & 68 & $\mathrm{~F}$ & Late crescendo & - & + & - & - & 6 & 12 \\
\hline & 12 & 73 & $F$ & Late crescendo & - & - & - & - & II & 14 \\
\hline & 13 & 82 & $\mathbf{M}$ & Pan & + & + & + & - & $-(\mathrm{AF})$ & 8 \\
\hline & 14 & 51 & $\mathbf{M}$ & Diamond & + & + & - & - & 16 & 20 \\
\hline & 15 & 19 & $\mathbf{F}$ & Diamond & + & + & + & - & 15 & 23 \\
\hline & 16 & 58 & $\mathbf{M}$ & Diamond & + & + & - & - & 17 & 24 \\
\hline & 17 & 62 & $\mathbf{M}$ & Pan & + & + & - & - & $-(\mathrm{AF})$ & 20 \\
\hline & 18 & 61 & $\mathbf{M}$ & Late crescendo & - & - & - & - & 25 & 34 \\
\hline & $19^{\star}$ & 58 & $\mathbf{F}$ & Diamond & + & + & - & - & 20 & 22 \\
\hline \multirow[t]{2}{*}{ Both cusps } & $20^{\star}$ & $6 I$ & $\mathbf{M}$ & Diamond & - & - & - & - & 18 & 20 \\
\hline & 21 & 55 & $\mathbf{M}$ & Pan & + & + & - & - & 18 & 32 \\
\hline
\end{tabular}

* Stretched chordae tendineae only; $S_{3}$, third heart sound; $A F$, atrial fibrillation.

with the ' $\mathrm{O}$ ' point of the displacement record, and invariably preceded $S_{3}$, which was recorded in all 3 patients. All patients with an early diastolic sound had posterior cusp chordal rupture (Table I). One of the 3 patients had a reduced ejection fraction.

A mid-diastolic murmur was recorded in only one patient. This patient, aged 7 , also was the only patient who did not have a pansystolic murmur. A displacement record had not been carried out on this patient, so that the character of the rapid filling wave could not be determined.

\section{Fourth heart sound and ' $a$ ' wave}

Although phonocardiograms were made using medium frequency filters in the mitral area, only one patient had a fourth heart sound $\left(\mathrm{S}_{4}\right)$ recorded. However, the relative height of the ' $a$ ' wave in the left ventricular displacement record was increased (Fig. 3) in all but 2 patients (normal value in this laboratory <II\%). Two patients were in atrial fibrillation and one did not have a record carried out. There was a positive and significant correlation between the height of the ' $a$ ' wave and the left ventricular diastolic pressure (usually the height of the ' $a$ ' wave), though the correlation was of little predictive value $(r=0.46, P<0.05)$ (Fig. 4). There were no significant differences between the ' $a$ ' wave height in patients with aortic or with posterior cusp detachment or stretching, nor in those with or without normal ejection fractions.

\section{Second heart sound}

The features of the second heart sound $\left(S_{2}\right)$ and their relation to pulmonary artery pressure are shown in Table 2. In 3 patients it was impossible to identify both $A_{2}$ and $P_{2}$. Splitting of $S_{2}$ in the remaining 18 patients was normal in $9(50 \%)$ but abnormally wide in expiration ( $>0.02 \mathrm{sec}$ ) in 9 $(50 \%)$. All patients had normal increase in splitting in inspiration (Fig. 5). Normal or wide expiratory splitting did not relate to the height of the pulmonary artery pressure, nor to the cusp affected, nor to left ventricular function.

The relative intensity of $\mathbf{P}_{2}$ and $\mathbf{A}_{2}$ in the pulmonary area was $P_{2}>A_{2}$ in 14 patients $(78 \%)$, $P_{2}=A_{2}$ in 2 patients (II\%), and $P_{2}<A_{2}$ in 2 patients (II\%). The patients with $P_{2}<A_{2}$ had relatively low pulmonary artery pressures.

\section{Systolic time intervals}

Systolic time intervals were measured in 18 patients, the 3 patients with left bundle-branch block or atrial fibrillation being excluded (Table 3). Left ventricular electromechanical systole and left ventricular 


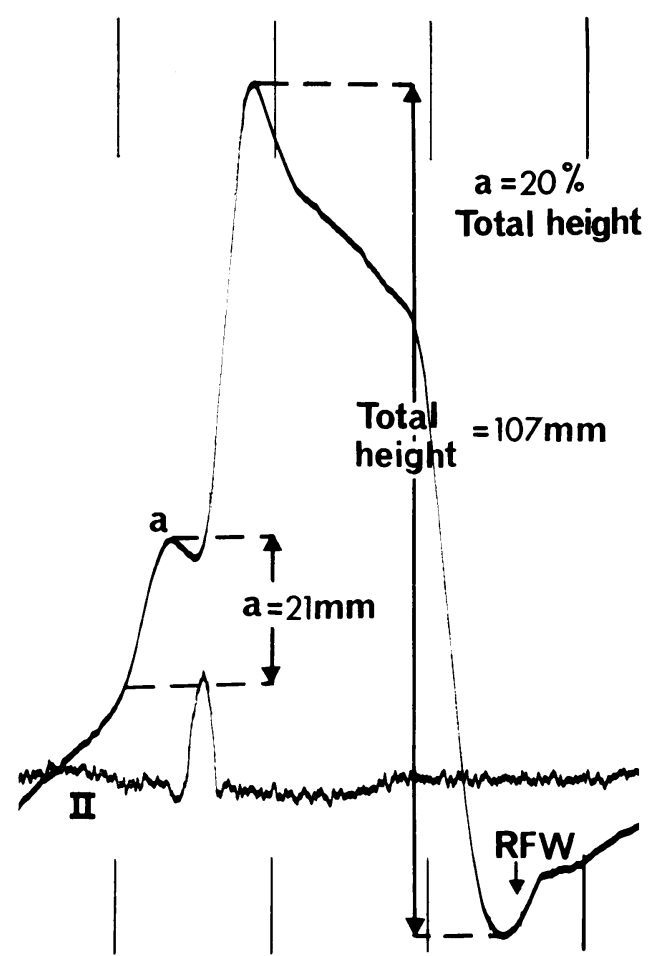

FIG. 3 Left ventricular displacement recorded simultaneously with electrocardiogram (lead II) in patient with ruptured chordae. The ' $a$ ' wave height is $21 \mathrm{~mm}$, the total height is $107 \mathrm{~mm}$, which gives a relative ' $a$ ' wave height of 20 per cent.

ejection time were significantly shorter than predicted normal values. The pre-ejection period, though usually shorter than normal, was not significantly different from normal (Table 4).

There were no significant differences in systolic time intervals between those patients with normal and those with wide expiratory splitting of the second heart sound. There were also no significant differences in systolic time intervals between those patients with aortic and those with posterior cusp detachment or stretching.

\section{Ejection fraction}

There was no significant correlation between systolic time intervals and ejection fraction (Table 5).

\section{Ejection fraction and aetiology}

There was a significant difference between the ejection fraction in patients who had an 'idiopathic' aetiology $(0.72 \pm 0.09)$ and those who had an 'infarct' aetiology $(0.45 \pm 0.12, P<0.001)$.

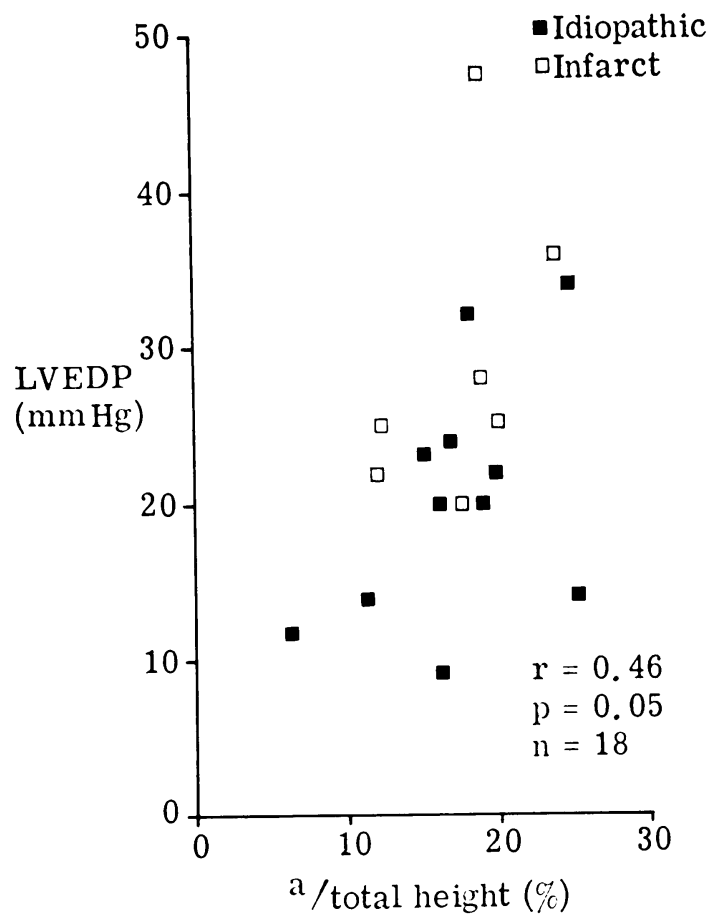

FIG. 4 Relation between left ventricular end-diastolic pressure and relative ' $a$ ' wave height. Patients divided according to 'idiopathic' or 'infarct' aetiology.

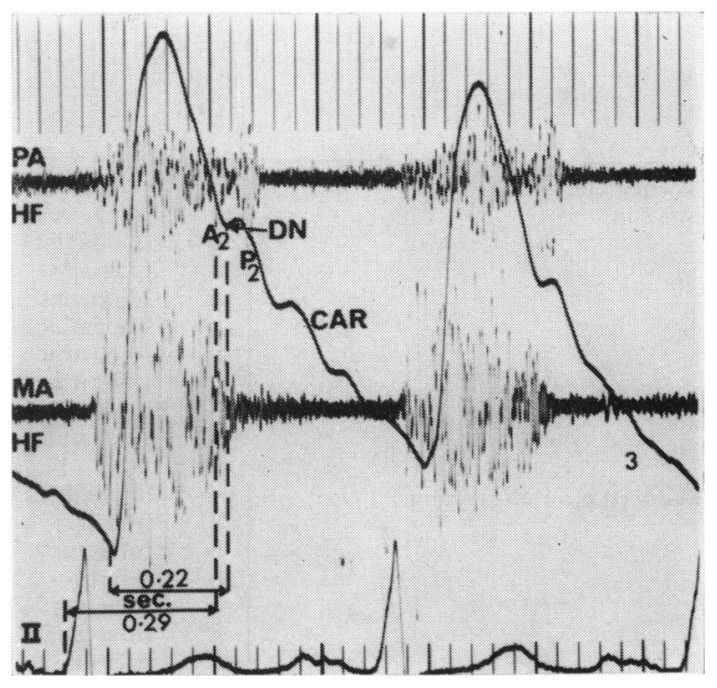

FIG. 5 Measurement of systolic time intervals. $Q-A_{2}=0.29 \sec (L V$ electromechanical systole) and LV ejection time $=0.22$ sec. Pre-ejection period is therefore $0.07 \mathrm{sec}$. The dicrotic notch $(D N)$ of the carotid pulse $(C A R)$ assists in identifying $A_{2}$ and $P_{2}$ which are widely separated $(0.06 \mathrm{sec})$. 
TABLE 2 Characteristics of second heart sound related to pulmonary pressures, mitral cusp affected, and aetiology of chordae lesion

\begin{tabular}{|c|c|c|c|c|c|c|c|}
\hline \multirow{2}{*}{$\begin{array}{l}\text { Case } \\
\text { No. }\end{array}$} & \multirow[t]{2}{*}{ Cusp } & \multirow[t]{2}{*}{ Group } & \multirow{2}{*}{$\begin{array}{l}S_{2} \text { split } \\
(s e c)\end{array}$} & \multirow[t]{2}{*}{$S_{2}$ intensity } & \multicolumn{2}{|c|}{ Pulmonary artery pressure } & \multirow{2}{*}{$\begin{array}{l}\text { Pulmonary vascular } \\
\text { (arteriolar) resistance } \\
\left(\text { units } \times m^{2}\right)\end{array}$} \\
\hline & & & & & $\begin{array}{l}\text { Mean } \\
(m m H g)\end{array}$ & $\begin{array}{l}S / D \\
(m m H g)\end{array}$ & \\
\hline 2 & Aortic & Idiopathic & $\mathrm{A}_{2}$ alone & - & 20 & $33 / 14$ & $3 \cdot 6$ \\
\hline $\mathbf{I}$ & Aortic & Idiopathic & $0.03-0.05$ & $\mathbf{P}_{2}>\mathbf{A}_{2}$ & 22 & $25 / 20$ & $4 \cdot 4$ \\
\hline 10 & Posterior & Idiopathic & $0.04-0.05$ & $\mathbf{P}_{2}<\mathbf{A}_{2}$ & 25 & $33 / 15$ & $1 \cdot 6$ \\
\hline 12 & Posterior & Idiopathic & $0.04-0.07$ & $P_{2}=A_{2}$ & 27 & $37 / 18$ & $4 \cdot 5$ \\
\hline 13 & Posterior & Idiopathic & $0.01-0.03$ & $\mathbf{P}_{2}>\mathbf{A}_{2}$ & 27 & $40 / 13$ & $\mathbf{I} \cdot 0$ \\
\hline II & Posterior* & Idiopathic & $0.04-0.06$ & $\mathbf{P}_{2}<\mathbf{A}_{2}$ & 27 & $37 / 17$ & $4 \cdot 0$ \\
\hline 14 & Posterior & Idiopathic & $0.04-0.07$ & $P_{2}>A_{2}$ & 30 & $48 / 20$ & $3 \cdot 0$ \\
\hline 3 & Aortic^ & Infarct & $A_{2}$ alone & - & 32 & $40 / 22$ & $4 \cdot 6$ \\
\hline 15 & Posterior & Idiopathic & $0.02-0.04$ & $\mathbf{P}_{2}>\mathbf{A}_{2}$ & 33 & $54 / 20$ & 0.6 \\
\hline 16 & Posterior & Idiopathic & $0.03-0.06$ & $\mathbf{P}_{2}=\mathbf{A}_{2}$ & 38 & $60 / 27$ & 5.4 \\
\hline 5 & Aortic* & Infarct & $0-0.02$ & $\mathbf{P}_{2}>\mathbf{A}_{2}$ & 40 & $60 / 25$ & $5 \cdot 5$ \\
\hline 4 & Aortic & Idiopathic & $0.03-0.04$ & $\mathbf{P}_{2}>\mathbf{A}_{2}$ & 40 & $56 / 20$ & 5.0 \\
\hline 18 & Posterior & Idiopathic & $0.02-0.03$ & $\mathbf{P}_{2}>A_{2}$ & 43 & $65 / 25$ & $8 \cdot 6$ \\
\hline 17 & Posterior & Idiopathic & $\mathrm{A}_{2}$ alone & - & 45 & $60 / 30$ & $2 \cdot 7$ \\
\hline 6 & Aortic* & Infarct & $0.01-0.03$ & $\mathbf{P}_{2}>\mathbf{A}_{2}$ & 45 & $70 / 29$ & $8 \cdot 0$ \\
\hline 19 & Posterior ${ }^{\star}$ & Idiopathic & $0.03-0.05$ & $\mathbf{P}_{2}>\mathbf{A}_{2}$ & 48 & $65 / 37$ & $3 \cdot 0$ \\
\hline 7 & Aortic ${ }^{\star}$ & Infarct & $0.02-0.03$ & $\mathbf{P}_{2}>\mathbf{A}_{2}$ & 48 & $75 / 35$ & $I \cdot O$ \\
\hline 21 & Both & Idiopathic & $0-0.03$ & $\mathbf{P}_{\mathbf{2}}>\mathbf{A}_{\mathbf{2}}$ & 55 & $90 / 40$ & $7 \cdot 5$ \\
\hline 20 & Both $\star$ & Infarct & $0.02-0.04$ & $\mathbf{P}_{2}>\mathbf{A}_{2}$ & 56 & $80 / 40$ & $20 \cdot 0$ \\
\hline 8 & Aortic & Infarct & $0-0.03$ & $P_{2}>A_{2}$ & 66 & $90 / 50$ & $28 \cdot 0$ \\
\hline 9 & Aortic $\star$ & Infarct & $0.03-0.04$ & $\mathbf{P}_{2}>\mathbf{A}_{2}$ & 74 & I $10 / 50$ & $8 \cdot 5$ \\
\hline
\end{tabular}

* Stretched chordae only; $S_{2}$, second heart sound; $P_{2}$, pulmonary valve closure; $A_{2}$, aortic valve closure; $S / D$, systolic/diastolic.

TABLE 3 Aetiology and systolic time intervals related to ejection fraction

\begin{tabular}{|c|c|c|c|c|c|c|c|}
\hline & $\begin{array}{l}\text { Case } \\
\text { No. }\end{array}$ & Group & $\begin{array}{l}\text { Ejection } \\
\text { fraction }\end{array}$ & $\begin{array}{l}\text { Heart } \\
\text { rate }\end{array}$ & $\begin{array}{l}\text { Pre- } \\
\text { ejection } \\
\text { period }\end{array}$ & $\begin{array}{l}\Delta \text { Pre- } \\
\text { ejection } \\
\text { period }\end{array}$ & $\begin{array}{l}\text { Left } \\
\text { ventricular } \\
\text { ejection } \\
\text { time }\end{array}$ \\
\hline \multirow[t]{9}{*}{ Normal ejection fraction } & $\left(\begin{array}{l}\text { II } \\
13\end{array}\right.$ & $\begin{array}{l}\text { Idiopathic } \\
\text { Idiopathic }\end{array}$ & $\begin{array}{l}0.86 \\
0.83\end{array}$ & \multicolumn{2}{|c|}{ Atrial fibrillation } & -6 & 225 \\
\hline & 10 & Idiopathic & 0.81 & 82 & 90 & - Io & 190 \\
\hline & $\mathbf{I}$ & Idiopathic & 0.79 & 125 & 70 & $-\mathbf{I} \mathbf{I}$ & 230 \\
\hline & 16 & Idiopathic & 0.73 & 72 & 130 & +28 & 260 \\
\hline & 17 & Idiopathic & 0.71 & \multicolumn{2}{|c|}{ Atrial fibrillation } & & \\
\hline & 18 & Idiopathic & 0.68 & 60 & 80 & -27 & 300 \\
\hline & 12 & Idiopathic & 0.66 & 79 & 100 & $-\mathbf{I}$ & 270 \\
\hline & 4 & Idiopathic & 0.66 & 88 & 90 & -8 & 250 \\
\hline & 2 & Idiopathic & 0.64 & 79 & 100 & $+I$ & 230 \\
\hline \multirow[t]{7}{*}{ Reduced ejection fraction } & 15 & Idiopathic & 0.56 & 72 & 130 & +26 & 260 \\
\hline & 8 & Infarct & 0.54 & 86 & 80 & -19 & 210 \\
\hline & 7 & Infarct & 0.53 & 79 & 80 & -19 & 230 \\
\hline & 20 & Infarct & 0.52 & \multicolumn{3}{|c|}{ Left bundle-branch block } & \\
\hline & 5 & Infarct & 0.47 & 75 & 90 & -13 & 230 \\
\hline & 9 & Infarct & 0.43 & 60 & 100 & -7 & 300 \\
\hline & 6 & Infarct & 0.22 & 63 & 95 & - II & 260 \\
\hline \multirow[t]{4}{*}{ Ejection fraction not determined } & $(14$ & Idiopathic & 一 & 86 & 80 & -17 & 230 \\
\hline & 19 & Idiopathic & 一 & 100 & 95 & +2 & 225 \\
\hline & 21 & Idiopathic & 一 & 88 & 80 & -15 & 235 \\
\hline & 3 & Infarct & - & 79 & 95 & -4 & 225 \\
\hline
\end{tabular}

$\Delta$, deviation from normal. 


\section{Discussion}

An apical pansystolic murmur is the hallmark of patients with mitral regurgitation (Brigden and Leatham, 1953) regardless of the aetiology. In patients with mitral regurgitation due to ruptured chordae tendineae the quality and radiation of the murmur are frequently different from those associated with rheumatic mitral regurgitation (Osmundson, Callahan, and Edwards, 1958). In this series the quality of the murmur was usually 'diamondshaped'irrespective of the cusp involved, whether the chordae were ruptured or stretched, or of the functional state of the left ventricle. This study was not primarily concerned with the radiation of the murmur, though both in our experience and in that of others the radiation in patients with ruptured or stretched mitral chordae has always been widespread and has not permitted the accurate prediction of the involved cusp (Caves, Sutton, and Paneth, 1973; Ronan et al., 1971).

The pansystolic murmur frequently made the aortic component of the second heart sound inaudible producing the clinical impression that the second heart sound was single. However, phonocardiographic recording with simultaneous external carotid artery tracings identified aortic valve closure in the usual position before the carotid artery di-

\begin{tabular}{llll}
\hline $\begin{array}{l}\Delta \text { Left } \\
\text { ventricular } \\
\text { ejection } \\
\text { time }\end{array}$ & $\begin{array}{l}\text { Left } \\
\text { ventricular } \\
\text { electro- } \\
\text { mechanical } \\
\text { systole }\end{array}$ & $\begin{array}{l}\Delta \text { Left } \\
\text { ventricular } \\
\text { electro- } \\
\text { mechanical } \\
\text { systole }\end{array}$ & $\begin{array}{l}\text { Ratio of pre-ejection } \\
\text { period to left } \\
\text { ventrime }\end{array}$ \\
\hline-65 & 320 & -71 & 0.42 \\
-97 & 280 & -107 & 0.47 \\
+29 & 300 & +18 & 0.30 \\
-31 & 390 & -3 & 0.50 \\
-11 & 380 & -38 & 0.27 \\
-22 & 370 & -23 & 0.37 \\
-27 & 340 & -35 & 0.36 \\
-49 & 330 & -48 & 0.43 \\
-43 & 390 & -17 & 0.50 \\
-70 & 290 & -89 & 0.38 \\
-49 & 310 & -68 & 0.35 \\
-68 & 320 & -81 & 0.39 \\
-11 & 400 & -18 & 0.33 \\
-46 & 355 & -57 & 0.36 \\
-37 & 310 & -54 & 0.35 \\
-33 & 320 & -31 & 0.42 \\
-28 & 315 & -43 & 0.34 \\
-54 & 320 & -58 & 0.42 \\
\hline & & & \\
\hline & & & \\
\hline
\end{tabular}

TABLE 4

\begin{tabular}{llll}
\hline & $\begin{array}{l}\text { Pre-ejection } \\
\text { period } \\
(\mathrm{msec})\end{array}$ & $\begin{array}{l}\text { Left ventricu- } \\
\text { lar ejection } \\
\text { time } \\
(\mathrm{msec})\end{array}$ & $\begin{array}{l}\text { Left ven- } \\
\text { tricular } \\
\text { electro- } \\
\text { mechanical } \\
\text { systole } \\
(\mathrm{msec})\end{array}$ \\
\hline $\begin{array}{l}\text { Observed } \\
\begin{array}{l}\text { Predicted normal } \\
\text { (Weissler } \text { et al., } \\
\text { I968) }\end{array}\end{array}$ & $93 \pm 3.7$ & $242 \pm 6.7$ & $335 \pm 8.6$ \\
$\begin{array}{c}\text { Deviation from } \\
\text { predicted normal }\end{array}$ & $99 \pm \mathrm{I} \cdot 3$ & $28 \mathrm{I} \pm 5.7$ & $38 \mathrm{I} \pm 7.4$ \\
$\begin{array}{c}\text { Significance of } \\
\text { difference }\end{array}$ & $\mathrm{P}<0.10$ & $\mathrm{P}<0.00 \mathrm{I}$ & $\mathrm{P}<0.00 \mathrm{I}$ \\
\hline
\end{tabular}

Mean values with standard error of mean given.

crotic notch, with pulmonary valve closure following the notch. This auscultatory difficulty with identification of aortic valve closure is a feature of situations in which there is a pansystolic murmur, as in ventricular septal defect and mitral regurgitation (Leatham, 1970). The murmur sometimes extended beyond aortic valve closure, presumably while left ventricular pressure continued to exceed left atrial pressure in the period of isometric relaxation (Wiggers and Feil, 1922).

In 50 per cent of the patients the splitting of the second heart sound was abnormal in that the expiratory split was greater than $0.02 \mathrm{sec}$ (Harris and Sutton, I968). Wide splitting of the second heart sound may be due either to relatively early aortic valve closure, or to relatively late pulmonary valve closure, or to both factors. Comparison with normal values for left heart systolic time intervals at similar heart rates derived from the data of Weissler et al. (1968) showed that this series of patients had significantly shorter left ventricular electromechanical systole and left ventricular ejection time than normal. Thus one explanation for the wide splitting of $S_{2}$ in some of these patients could be abnormally early aortic valve closure. However, there were no significant

TABLE 5

\begin{tabular}{|c|c|}
\hline & Ejection fraction \\
\hline $\begin{array}{l}\text { Pre-ejection period } \\
\Delta \text { Pre-ejection period } \\
\text { Left ventricular ejection time } \\
\Delta \text { Left ventricular ejection time } \\
\text { Pre-ejection period/left ventricular ejection } \\
\quad \text { time }\end{array}$ & $\begin{array}{l}r=-0.05 \\
r=-0.14 \\
r=0.33 \\
r=0.05 \\
r=0.21\end{array}$ \\
\hline
\end{tabular}

$\Delta=$ Deviation from predicted normal value.

$\mathbf{r}=$ Correlation coefficient. 
differences in the shortening of left ventricular electromechanical systole and ejection time between those patients with abnormally wide and those with normal splitting of the second heart sound, indicating that other factors are implicated in determining the splitting of the second heart sound. In the majority of patients there was no respiratory variation in left ventricular electromechanical systole $\left(\mathrm{Q}-\mathrm{A}_{2}\right)$ so that the increased split during inspiration was due to prolongation of right ventricular electromechanical systole $\left(\mathrm{Q}-\mathrm{P}_{2}\right)$ and this has previously been noted to be a feature of patients with mitral regurgitation and pulmonary hypertension (Sutton, Harris, and Leatham, 1968).

The presence of an atrial sound in patients with ruptured mitral chordae tendineae has occasionally been noted (Raftery, Oakley, and Goodwin, 1966; Sanders et al., 1967). Cohen, Mason, and Braunwald (1967) suggested that it was a useful clinical sign in the diagnosis of ruptured chordae. Though atrial sounds were not usually heard or recorded in this series, nevertheless increased left atrial activity was demonstrated by increase in the height of the ' $a$ ' wave of the apical displacement record in all but two patients. Such a discrepancy between auscultation and palpation is not surprising, as palpation (or the displacement record) may be more sensitive in revealing increased atrial activity than auscultation (or a phonocardiogram), as the frequency range of this aspect of cardiac vibration is low.

The presence of large ' $a$ ' waves in mitral regurgitation secondary to ruptured chordae contrasts with inconspicuous ' $a$ ' waves (and absent atrial sounds) in those patients who are in sinus rhythm with rheumatic mitral regurgitation or mitral stenosis. It has been postulated that the sudden development and shorter duration of mitral regurgitation in patients with ruptured chordae permits vigorous atrial contraction to occur in a previously normal left atrium, whereas chronic rheumatic heart disease causes alterations in the atrial wall which make it unable to contract vigorously under the demand of severe volume overloading (Cohen et al., 1967).

The increased ' $a$ ' wave was related to the increased left ventricular diastolic pressure (usually taken as the ' $a$ ' wave height) in these patients with ruptured chordae. Similar relations have been demonstrated in patients with other heart disease (Dimond and Benchimol, 1963; Voigt and Friesinger, 1970; Fleming, 1968). The wide variation in ' $a$ ' wave height and left ventricular diastolic pressure may be explained by variations in compliance of both left ventricle and left atrium, which may change with the passage of time. Thus chordal rupture seen shortly after the event may result in a pronounced rise in pressure in response to volume loading in a fairly non-complaint chamber, whereas long-standing severe mitral regurgitation usually results in considerable left ventricular and left atrial dilatation, with consequent reduction in the initially raised pressures.

Although a third heart sound was frequently heard and recorded in this series, it was not almost invariable, as reported by others (Raftery et al., 1966; Sanders et al., 1967; Cohen et al., 1967; Roberts, Braunwald, and Morrow, 1966). We agree with Fleming (1969) and Ikram, Makey, and Bliss (1969) that in mitral regurgitation a third sound is accompanied by an abrupt retraction of the cardiac apex in early diastole (the 'third sound point'). Analysis of the apical displacement records in this series of patients showed that a third heart sound was invariably associated with an obvious 'third sound point'. There were 3 other patients who had a 'third sound point' but no recordable (or audible) third sound, emphasizing the low-frequency nature of this cardiac vibration.

The mechanism of production of the third sound in mitral regurgitation remains a controversial subject. Early closure of the mitral valve (Gibson, 1907; Thayer, 1909) has not been substantiated by ultrasound analysis of mitral valve movement which showed the aortic leaflet to be in an intermediate position at the time of the third sound (Fleming, 1969). Sudden tautening of the valve and the subvalvar structures has been an alternative hypothesis (Fleming, 1969; Ikram et al., 1969; Dock, 1959; Nixon, 196I), but third heart sounds in patients with heterograft mitral valve replacement (El Gamal and Smith, 1970) or after homograft mitral valve replacement (Gianelly, Popp, and Hultgren, 1970; G. C. Sutton, 1971, unpublished data) have been recorded. Whether such observations support the ventricular dilatation theory of third sound production (Potain, 1900; Kuo, Hildreth, and Kay, I95 ; Crevasse et al., 1962) or whether there is a yet further mode of production of the third sound remains unproven.

In this series of patients we have been unable to demonstrate that selective involvement of either one cusp or one papillary muscle is responsible for the presence or absence of the third sound, though a posterior cusp lesion was more commonly associated with a third sound. Equally, both patients with stretched chordae and those with chordal rupture had third sounds and 'third sound points'.

Three patients had an additional high-frequency diastolic sound. All had rupture of the posterior leaflet and all had a third sound. Similar findings have not previously been reported, though Giuliani (1967) showed a phonocardiogram with an early diastolic sound, but without clearly demonstrating aortic and pulmonary valve closure or a 
third sound separate from this sound. The additional sound coincided in timing with the ' $O$ ' point of the displacement record, suggesting that it might be related to mitral valve opening. If this sound were an 'opening snap' of the mitral valve it might be similar in genesis to the opening snap heard in some patients with dominant rheumatic mitral regurgitation. Such patients (Nixon, Wooler, and Radigan, 1960) were shown to have a pliant aortic cusp with disease of the posterior cusp causing the regurgitation.

Various authors have described mid-diastolic murmurs in the mitral area in patients with ruptured chordae (Raftery et al., 1966; Roberts et al., 1966; Giuliani, 1967). We have adopted Perloff and Harvey's definition of a mid-diastolic murmur as a series of vibrations lasting $0 \cdot 10 \mathrm{sec}$ or more, by contrast with the shorter duration third sound (Perloff and Harvey, 1962), and we heard and recorded such a murmur in only one patient, the youngest in the series. It seems likely that in previous series patients were included who had rheumatic mitral valve disease with chordal rupture and in whom some degree of mitral stenosis was also present.

Phonocardiography, left ventricular displacement records, and systolic time intervals did not identify patients with impaired left ventricular function as judged by ejection fraction. Changes in pre-ejection period and left ventricular ejection time and the ratio between them have been found useful in identifying patients with arteriosclerotic, hypertensive, and primary myocardial disease who had impaired left ventricular function (Weissler, Harris, and Schoenfeld, 1969). A significant correlation has also been reported between changes in pre-ejection period and left ventricular ejection time and the ratio between them, and angiographically determined ejection fraction in patients with various cardiac abnormalities, including isolated mitral regurgitation (Garrard, Weissler, and Dodge, 1970). Yet in the present study there was no significant correlation between changes in pre-ejection period, left ventricular ejection time, or the ratio between them in patients with normal or impaired left ventricular function, as judged by ejection fraction.

Systolic time intervals are influenced by changes in inotropic state, forward stroke volume, heart rate, aortic diastolic pressure, and left ventricular enddiastolic pressure (Weissler et al., 1968; Talley, Meyer, and McNay, 197I). Though the patients reported here all had severe mitral regurgitation, forward stroke volume varied from patient to patient. Aortic diastolic pressure may have remained reasonably constant throughout the group, but left ventricular end-diastolic pressure ranged from normal to very high values in different patients
(Table I). As such important determinants of systolic time intervals were inconstant from patient to patient, it is not surprising that there was no significant relation between systolic time intervals and one other determinant - the ejection fraction. Furthermore, in patients with free mitral regurgitation a true isovolumic contraction period does not exist; therefore alterations in pre-ejection period (which not only includes the electromechanical interval and the onset of left ventricular pressure rise to the onset of the first heart sound, but also the isovolumic contraction period) will be influenced conspicuously by the instantaneous changes in the pressure-volume relation of the ventricle during the period from the first heart sound to the opening of the aortic valve.

We would like to thank Dr. R. V. Gibson for permission to report patients admitted under his care and Mr. M. Paneth and Mr. S. C. Lennox, who carried out the surgical treatment of these patients, for the operative details.

\section{References}

Brigden, W., and Leatham, A. (1953). Mitral incompetence. British Heart fournal, $15,55$.

Caves, P. K., and Paneth, M. (1972). Acute mitral regurgitation in pregnancy due to ruptured chordae tendineae. British Heart fournal, 34, 54I.

Caves, P. K., Sutton, G. C., and Paneth, M. (1973). Nonrheumatic sub-valvar mitral regurgitation. Aetiological and clinical aspects. Circulation. In the press.

Chatterjee, K., Sacoor, M., Sutton, G. C., and Miller, G. A. H. (197I). Assessment of left ventricular function by single plane cineangiographic volume analysis. British Heart fournal, 33, 565 .

Cohen, L. S., Mason, D. T., and Braunwald, E. (1967). Significance of an atrial gallop sound in mitral regurgitation. Circulation, 35, II2.

Crevasse, L., Wheat, M. W., Wilson, J. R., Leeds, R. F., and Taylor, W. J. (1962). The mechanism of the generation of the third and fourth heart sounds. Circulation, 25, 635.

Dimond, E. G., and Benchimol, A. (1963). Correlation of intracardiac pressure and praecordial movement in ischaemic heart disease. British Heart fournal, 25, 389.

Dock, W. (1959). The forces needed to evoke sounds from cardiac tissues, and the attenuation of heart sounds. Circulation, 19, 376.

Edwards, J. E., and Burchell, H. B. (1958). Endocardial and intimal lesions (jet impact) as possible sites of origin of murmurs. Circulation, 18, 946.

El Gamal, M., and Smith, D. R. (1970). Occurrence of a left ventricular third heart sound in incompetent mitral heterografts. British Heart fournal, 32, 497.

Fleming, J. S. (1968). The assessment of failure in aortic stenosis from the diastolic movements of the left ventricle. American Heart fournal, 76, 235.

Fleming, J. S. (1969). Evidence for a mitral valve origin of the left ventricular third heart sound. British Heart fournal, 31, 192.

Garrard, C. L., Weissler, A. M., and Dodge, H. T. (1970). The relationship of alterations in systolic time intervals to ejection fraction in patients with cardiac disease. Circulation, 42, 455 . 
Gianelly, R. E., Popp, R. L., and Hultgren, H. N. (1970). Heart sounds in patients with homograft replacement of the mitral valve. Circulation, 42, 309.

Gibson, A. G. (1907). The significance of a hitherto undescribed wave in the jugular pulse. Lancet, 2, 1380 .

Giuliani, E. R. (1967). Mitral valve incompetence due to flail anterior leaflet. American fournal of Cardiology, 20, 784 .

Harris, A., and Sutton, G. (1968). Second heart sound in normal subjects. British Heart fournal, 30, 739.

Ikram, H., Makey, A. R., and Bliss, B. P. (1969). Genesis of diastolic sounds in mitral incompetence. British Heart Fournal, 31, 762.

Kuo, P. T., Hildreth, E. A., and Kay, C. F. (I95I). The mechanism of gallop sounds, studied with the aid of the electrokymograph. Annals of Internal Medicine, 35, 1306.

Leatham, A. (1970). Auscultation of the Heart and Phonocardiography. Churchill, London.

Nixon, P. G. F. (196I). The third heart sound in mitral regurgitation. British Heart fournal, 23, 677.

Nixon, P. G. F., Wooler, G. H., and Radigan, L. R. (1960). The opening snap in mitral incompetence. British Heart Fournal, 22, 395.

Osmundson, P. J., Callahan, J. A., and Edwards, J. E. (1958). Mitral insufficiency from ruptured chordae tendineae simulating aortic stenosis. Proceedings of the Staff Meetings of the Mayo Clinic, 33, 235.

Perloff, J. K., and Harvey, W. P. (1962). Auscultatory and phonocardiographic manifestations of pure mitral regurgitation. Progress in Cardiovascular Diseases, 5, 172.

Potain, C. E. (1900). Les bruits de galop. Semaine Médicale, 20, 175 .

Raftery, E. B., Oakley, C. M., and Goodwin, J. F. (1966). Acute subvalvar mitral incompetence. Lancet, 2, 360.

Roberts, W. C., Braunwald, E., and Morrow, A. G. (1966). Acute severe mitral regurgitation secondary to ruptured chordae tendineae. Circulation, 33, 58.

Ronan, J. A., Steelman, R. B., DeLeon, A. C., Waters, T. J., Perloff, J. K., and Harvey, W. P. (197I). The clinical diagnosis of acute severe mitral insufficiency. American fournal of Cardiology, 27, 284.

Sanders, C. A., Austen, W. G., Harthorne, J. W., Dinsmore, R. E., and Scannell, J. G. (1967). Diagnosis and surgical treatment of mitral regurgitation secondary to ruptured chordae tendineae. New England fournal of Medicine, 276, 943.

Sanders, C. A., Scannell, J. G., Harthorne, J. W., and Austen, W. G. (1965). Severe mitral regurgitation secondary to ruptured chordae tendineae. Circulation, 31, 506.

Selzer, A., Kelly, J. J., Vannitamby, M., Walker, P., Gerbode, F., and Kerth, W. J. (1967). The syndrome of mitral insufficiency due to isolated rupture of the chordae tendineae. American fournal of Medicine, 43, 822.

Sutton, G., Harris, A., and Leatham, A. (1968). Second heart sound in pulmonary hypertension. British Heart fournal, 30, 743 .

Talley, R. C., Meyer, J. F., and McNay, J. L. (197I). Evaluation of the pre-ejection period as an estimate of myocardial contractility in dogs. American fournal of Cardiology, 27, 384 .

Thayer, W. S. (1909). Further observations on the third heart sound. Archives of Internal Medicine, 4, 297.

Voigt, G. C., and Friesinger, G. C. (1970). The use of apexcardiography in the assessment of left ventricular diastolic pressure. Circulation, 4r, I0I5.

Weissler, A. M., Harris, W. S., and Schoenfeld, C. D. (I968). Systolic time intervals in heart failure in man. Circulation, 37, 149.

Weissler, A. M., Harris, W. S., and Schoenfeld, C. D. (1969). Bedside technics for the evaluation of ventricular function in man. American fournal of Cardiology, 23, 577.

Wiggers, C. J., and Feil, H. (I922). The cardiodynamics of mitral insufficiency. Heart, 9, 149.

Requests for reprints to Dr. G. C. Sutton, Department of Cardiology, Brompton Hospital, London S.W.3. 